\title{
O coaching como instrumento de desenvolvimento de recursos humanos
}

\author{
SOARES, Luciana ${ }^{1}$ \\ luciana.rocha.soares@gmail.com \\ Universidade de Évora \\ SERRANO, Maria Manuel ${ }^{2}$ \\ mariaserrano@uevora.pt \\ Universidade de Évora e SOCIUS-ISEG/UTL
}

\begin{abstract}
Resumo
Este paper baseia-se num projecto de investigação que sustenta a elaboração de uma dissertação de Mestrado em Sociologia. A estratégia metodológica definida centra-se no estudo de casos de Directores de Recursos Humanos que tenham frequentado e concluído o curso de coaching entre 2005 e 2010 e que estejam actualmente a exercer a função. O principal objectivo do trabalho consiste em identificar o contributo da formação em coaching dos Directores de Recursos Humanos e a forma como estes transferem os conhecimentos adquiridos para os seus contextos organizacionais. Pretende-se ainda, reconhecer as mudanças que o curso proporcionou ao nível pessoal e profissional e identificar as potencialidades do coaching enquanto instrumento de DRH. Este texto apresenta uma breve reflexão em torno dos conceitos centrais da investigação - coaching, desenvolvimento de recursos humanos e competências.
\end{abstract}

Palavras chave: Coaching, desenvolvimento de recursos humanos e competências.

\section{Introdução}

As mudanças em curso na sociedade actual provocam, inevitavelmente, alterações no universo organizacional. Este contexto exige, da parte dos gestores de recursos humanos, uma actuação específica em domínios vários como a comunicação, o desenvolvimento de competências, a sustentação dos níveis de motivação do pessoal ou a adaptação à mudança.

O desenvolvimento organizacional, enquanto processo de mudança e de adaptação da organização à mudança, assente em princípios participativos e democráticos, tende a valorizar o papel das pessoas no planeamento e implementação de estratégias organizacionais. Nos processos de mudança, a formação contínua do capital humano assume um papel crucial, na medida em que potencia a renovação das competências e as capacidades de adaptação às mudanças.

\footnotetext{
${ }^{1}$ Aluna do Mestrado em Sociologia da Universidade de Évora.

${ }^{2}$ Professora Auxiliar no Departamento de Sociologia da Universidade de Évora.
} 
IV Conferência Investigação e Intervenção em Recursos Humanos - Os Novos Contextos da Gestão de Recursos Humanos

Na perspectiva do desenvolvimento de recursos humanos (DRH), os indivíduos são seres únicos, providos de competências, talentos e capacidades exclusivas. O desenvolvimento do capital humano, possível através da aplicação de práticas e estratégias formativas, promove um aperfeiçoamento de competências, assumindo uma importância acrescida na competitividade organizacional.

Neste contexto, o coaching surge como uma prática formativa, continuada e planeada, de aperfeiçoamento, cujo objectivo principal é modificar os comportamentos, promovendo o desenvolvimento individual e organizacional, num contexto de transformação e aprendizagem contínuas (Cunha, Rego, Cunha, Cardoso, Marques e Gomes, 2010).

Esta comunicação tem por base um projecto de investigação com vista à elaboração de uma dissertação, no âmbito do Mestrado em Sociologia da Universidade de Évora. O principal objectivo traçado visa identificar o contributo da formação em coaching dos Directores de Recursos Humanos e a forma como estes transferem os conhecimentos adquiridos para os seus contextos organizacionais. Pretende-se ainda, reconhecer as mudanças que o curso proporcionou ao nível pessoal e profissional e identificar as potencialidades do coaching enquanto instrumento de DRH. 